\title{
A INTERNET E A INCLUSÃO SOCIAL: \\ REFLEXOS DA UTILIZAÇÃO DE SISTEMAS COMPUTACIONAIS PELO PODER JUDICIÁRIO NA REALIZAÇÃO DA "INFOINCLUSÃO"
}

\author{
Alexia A. Rodrigues Brotto \\ Cinthia O. de A. Freitas ${ }^{\star *}$
}

\section{RESUMO}

Com as mudanças tecnológicas, de grande impacto sobre a sociedade, - Direito e também o Poder Judiciário são desafiados a adequar seus procedimentos, reformular conceitos e atender as mais variadas demandas que Ihe são apostas. De fato, se a realidade social já não é mais a mesma, e o avanço da tecnologia e informática alteram substancialmente os mais diversos ramos da sociedade, o Poder Judiciário como prestador de serviço público não pode ser avesso à essa questão, devendo inclusive, além de possibilitar integração e utilização de sistemas computacionais na persecução de maior celeridade, dinamismo e menor custo processual, preocupar-se com a questão do acesso da população não só a essa nova realidade tecnológica, mas também o acesso à informação, conhecimento, informatização e à própria Justiça. Neste diapasão, muito se tem ainda a projetar e implantar para tentar acolher a toda a população brasileira, fazendo com que essa inclusão digital não se resuma a uma exclusão social. Por isso a necessidade de cada vez mais, modernizar todas as esferas estatais, inclusive adequando-se o Poder Judiciário à essa realidade da digitalização e informatização dos sistemas adotados, sem, contudo, esquecer-se das camadas menos favorecidas.

Palavras-chave: Inclusão digital. Inclusão social. Poder Judiciário. Sistemas computacionais. Tecnologia.

\section{INTRODUÇÃO}

O presente trabalho contribui para uma análise sucinta a respeito da revolução tecnológica operada no mundo, trazendo reflexos importantes para a área do Direito, sobretudo no que diz respeito aos procedimentos realizados pelo Poder Judiciário na tentativa de inclusão social.

Nesse ambiente de revolução paradigmática, da sociedade complexa, informatizada, cabe relatar os avanços da tecnologia com sistemas computacionais para o Poder Judiciário, viabilizando o peticionamento eletrônico, citações, intimações via e-mail e todo o acompanhamento e anexação de documentos para propositura de demandas pela Internet. Essa foi inicialmente a proposta dos sistemas e-proc e e-cint, surtindo valiosos reflexos na aplicabilidade da Lei $n^{\circ}$. 11.419/2006 que, dentre outras providências, aclarou a sistematização desses programas computacionais. 
De fato, reflete um enorme avanço no Poder Judiciário, no entanto, colima proporcionar que num país como o Brasil, nem todas as pessoas possuem acesso ao computador, Internet, e não raras vezes acesso à própria informação. De forma que não basta apenas o investimento em tecnologias para um Judiciário mais célere e eficaz, se não há investimento na sociedade com políticas públicas para a informação, informatização, a fim de que a inclusão digital não se resuma em exclusão social.

\title{
1 A MUDANÇA DE PARADIGMAS
}

Generoso aporte à teoria da mudança de paradigmas (emergente ou da complexibilidade) defronta-se nas obras de Boaventura de Sousa Santos ( $A$ Crítica da Razão Indolente, 2000), Fritjof Capra (A Teia da Vida, 1996 e As Conexões Ocultas, 2002) e Edgar Morin (O Paradigma perdido: a natureza humana, 1973 e Os sete saberes necessários à educação do futuro, 2000).

Disse SOUSA SANTOS (2000, p. 164) que a ciência moderna contribuiu para transformar 0 conhecimento científico num conhecimento regulador hegemônico, "que absorveu em si o potencial emancipatório do novo paradigma", qual seja da "pós-modernidade" ou simplesmente complexidade.

Em relação ao avanço tecnológico, imerso nesta complexidade social, esclarecem CASTEJON e MONTES (Anais, 2001, p. 161):

\begin{abstract}
Durante o decorrer dos 12 últimos anos o crescimento do número de equipamentos eletrônicos conectados e de serviços disponibilizados através da Internet foi acompanhado do aumento de complexidade nas infraestruturas da tecnologia de informação. No entanto, a capacidade pessoal de compreender e acompanhar todo este crescimento não teve o mesmo desenvolvimento.
\end{abstract}

Vivemos, então, uma situação de transição - do direito, da ciência, da sociedade - cujo responsável muitas vezes é o descompasso entre o excesso de desenvolvimento de uma área e o subdesenvolvimento de outra, recaindo no abstracionismo das relações e aversão aos novos direitos, à tecnologia etc., ora por desconhecimento, ora por incompreensão.

De fato, são as transformações sociais, políticas e econômicas, bem como seu o contexto histórico, que orientam o alcance e desenvolvimento da revolução tecnológica ${ }^{1}$. No entanto, a ciência, como desenvolvedora de novos projetos e concepções, teoricamente proposta como um sistema aberto, passa a ser brutalmente funcionalizada à favor do capitalismo ${ }^{2}$, diminuindo seu potencial de visão emancipatória, uma vez que o conhecimento científico ao se transformar em conhecimento regulador hegemônico, inviabiliza o potencial emancipatório de um novo paradigma nascente.

Porém, foi justamente por meio da expansão capitalista e da globalização que se tornou possível o acesso à informação pela rede mundial de computadores. Ou seja, a globalização, muitas vezes enxergada como destruidora da emancipação social por promover a hegemonia e regulação, é 
que trouxe o maior acesso ao computador e internet, viabilizando, também, menores preços para sua aquisição. Reconhecendo o papel preponderante da Internet na sociedade atual como revolução paradigmática, explica CASTELLS (In MORAES, 2005, p. 287):

\begin{abstract}
A Internet não é simplesmente uma tecnologia; é o meio de comunicação que constitui a forma organizativa de nossas sociedades; é o equivalente ao que foi a fábrica ou a grande incorporação na era industrial. A Internet é o coração de um novo paradigma sociotécnico, que constitui na realidade a base material de nossas vidas e de nossas formas de relação, de trabalho e de comunicação. O que a Internet faz é processar a virtualidade e transformá-la em nossa realidade, constituindo a sociedade em rede, que é a sociedade em que vivemos.
\end{abstract}

E com a difusão cada vez maior dessa realidade: o sistema computacional, a rede mundial interligando pessoas e fatos em tempos reais, verifica-se que $o$ Direito e até mesmo a própria sociedade não estão, integralmente preparados para absorver essa realidade que se destaca e cada dia mais sofre avanços tecnológicos, trazendo maiores benefícios, sem mencionar o conforto que a Internet traz aos usuários no sentido da comunicação, contratação e visualização do mundo.

Mas não só de benefícios compõem-se a internet e o mundo digital nesse paradigma emergente que, embora ainda despreparado, se sobrepõe ao Direito e órgãos judiciais. Para BEHRENS (2005, p. 10):

Face a este desenvolvimento os mais diversos segmentos econômicos e sociais vêm sendo desafiados a adaptar-se e reestruturar conceitos e princípios diante das dinâmicas inovações concretizadas por meio dos mais diversos métodos tecnológicos.

Ora, a sociedade é complexa ${ }^{3}$. E o paradigma da complexidade ${ }^{4}$, abrangendo uma sociedade cada vez mais global e cada vez mais única (IANNI, 1994, p. 157) incita a juridicização da economia, da política, dos fenômenos sociais e da própria sociedade. E, sob o respaldo da inclusão e da intercomunicação acaba-se juridicizando o mundo social.

Mas o novo paradigma da complexidade, envolvendo questões tecnológicas sobre as quais o nosso Direito encontra-se incipiente não se assenta somente nessas questões. SOUSA SANTOS (2000, p. 164) entende que a discussão paradigmática do direito moderno em conjunto com a ciência moderna é que irá esclarecer os rumos da "transição para um novo paradigma societal", o qual, segundo CAPRA (2002, p. 17), deverá se propor a superar a dualidade entre estruturas materiais e sociais, bem como a dualidade de todos os seguimentos da sociedade.

De fato, o colapso da modernidade reflete-se nas questões críticas do conhecimento e em todos os ramos da ciência e culturalidade. Isso porque 0 sistema tradicional - ainda que calcado num capitalismo "organizado" - não consegue atender às demandas sociais, ao novo grupo de pessoas que se forma sob a máscara do consumismo; aos anseios políticos; aos novos direitos e novas concepções de ordenamento com a tendência do pluralismo jurídico e 
avanço tecnológico; as oscilações do mercado e contratações cada vez mais virtuais, esquecendo-se do homem ${ }^{5}$ como sujeito concreto de direitos ${ }^{6}$, ainda que na seara virtual se tenham homens cada vez mais abstratos no sentido de sua representatividade por meio de máquinas.

Nesse contexto, SOUSA SANTOS entende que o papel desempenhado pelo Direito - e acrescente-se ser também papel do Judiciário - é um papel central $^{7}$ nessas relações entre o que é tradicional e sedimentado na doutrina e dogmática jurídicas e as propostas de um porvir de inúmeras possibilidades, inclusive na seara virtual.

De fato, a transformação está ocorrendo há tempos, inclusive com promessas emancipatórias e científicas. Pensar nessa mudança, e pensar o modo como se pensa essa mudança, não é nem o começo, nem o fim, nem a premissa, nem a solução, mas uma reconstrução de saberes, conceitos, análise de possibilidades na caminhada para um novo paradigma societal, propiciando a inclusão, o conhecimento e as novas tecnologias que emergem da mutação social.

$E$ nesse contexto, a inclusão digital, o acesso à tecnologia e a informação da população tornam-se temas a ser enfrentado por todas as áreas do conhecimento e, no caso do Direito, elementos indispensáveis na elaboração e desenvolvimento de sistemas computacionais para o Poder Judiciário.

\section{FERRAMENTAS ATUAIS: O ESTADO DA ARTE}

Imperioso destacar o desenvolvimento do estado da tecnologia no cenário mundial para compreensão das ferramentas utilizadas, processos de automação, informatização dos serviços privados e públicos, acompanhando as transformações na vida social, tecnológica e científica até a chegada dos sistemas computacionais na seara do Poder Judiciário.

De fato, a Internet transformou-se no tecido de nossas vidas neste momento (CASLTELLS In MORAES, 2005, p. 255), pois por meio dela é possível uma maior interação da sociedade com o mundo, sem precisar sair da própria casa, muitas vezes, além da maior integração dos núcleos econômicos, políticos e culturais ${ }^{8}$. Essa relação homem com a máquina e as ferramentas a ela inerentes é explicada por CADOZ (1997, p. 62-63):

\footnotetext{
O homem está em relação com o seu meio ambiente para conhecer, agir, comunicar, transformá-lo e se transformar. [...]. Pela tecnologia, o homem prolongou-se. Prolongou sua mão com suas primeiras ferramentas, utilizando sua própria força para trabalhar a matéria. [...]. Com o auxílio da ferramenta, o homem modificou sua relação com o mundo. A ferramenta é ambivalente, pode ser considerada como uma extensão do sujeito para o objeto ou como fazendo parte dos objetos para o sujeito.
}

$\mathrm{Na}$ verdade, o computador inaugura uma nova era da tecnologia, cuja utilização tornou-se parte integrante da vida das pessoas (REIS e GEUS, 
Anais, 2001, p. 73). Mas não só isso, com o surgimento do computador também o panorama de estudos científicos relacionados a grafos altera-se substancialmente, viabilizando a implementação e computação automática dos algoritmos (SZWARCFITER, 1986, p. 20), o que possibilita maior praticidade na composição de sistemas computacionais por parte dos agentes programadores e maior facilidade e tráfego de informações, por parte dos usuários. Neste sentido NAZARENO, BOCCHIO, MENDES e PAZ FILHO (2007, p. 23-24):

\begin{abstract}
A popularização da Internet e o desenvolvimento de ferramentas tecnológicas como as fibras óticas e os sistemas de computação de alto desempenho têm permitido que não apenas dados, mas qualquer tipo de informação representada na forma de seqüências binárias áudio, vídeo ou texto - possa trafegar com desembaraço pela rede mundial de computadores. Nesse sentido, a convergência consiste na integração de serviços e de infra-estruturas de modo a oferecer um serviço contínuo e abrangente ao cidadão.
\end{abstract}

p. 13):

Igualmente e acrescendo, BARBOSA FILHO, CASTRO e TOMÉ (2005,

Nos últimos vinte anos, a revolução informática adquiriu tremenda velocidade, impulsionando a convergência tecnológica eliminando as fronteiras entre os meios tradicionais de comunicação e criando oportunidades interativas entre os agentes midiáticos. Mas, sem dúvida, a mais importante mudança no panorama vem ocorrendo pelo avanço da digitalização, gerando novíssimos meios e articulando-os simultaneamente com os velhos transmissores de conteúdo.

$\mathrm{Na}$ realidade, a relação da informática e tecnologia com o mundo não estão apenas nas relações sociais e científicas, a própria produtividade e 0 desenvolvimento econômico são e estão cada vez mais dependentes da aplicação de ciência e tecnologia (WARSCHAUER, 2006, p. 32), impulsionando os procedimentos hegemônicos e não-hegemônicos ao processo de integração, circulação, comercialização, e relacionamento social, propostos pelo avanço e difusão da tecnologia.

De fato, a partir da abertura e acesso à Internet ${ }^{9}$, a atividade social assume um novo papel, dinâmico e globalizado, rompendo as barreiras geopolíticas dos Estados, como forma de integração universal. Com a expressiva facilidade de comunicação e o desenvolvimento da tecnologia e globalização ${ }^{10}$, o mundo não só dos negócios destaca modalidades tecnológicas antes nunca vistas, como as práticas de comércio eletrônico e o atual processo eletrônico, de que serve alguns órgãos judiciais.

Muitos autores definem essa sociedade atual como representante da "Era da Informação", que sem dúvida alguma é evidenciada sob os mais variados aspectos: social, filosófico e artístico, como defende SANTOS LEAL (2003, p. 4-5):

$\mathrm{Na}$ 'sociedade da informação', a riqueza econômica e a concentração de poder não mais têm por pressuposto a detenção de terras ou dos meios de produção, mas sim a possibilidade de acesso às tecnologias de produção e, especialmente, ao mercado consumidor, ou seja, à própria informação. 
Acrescendo, BARRETO (2005, p. 115):

É preciso destacar muitos aspectos, dentre eles as transformações tecnológicas, organizacionais geopolíticas, comerciais e financeiras, institucionais, culturais e sociais, para uma melhor compreensão da gênese desta Sociedade da Informação.

Contudo, as alterações nos processos comunicacionais e no cenário econômico mundial serão de interesse maior nesta discussão, já que se articulam e estão ligados, diretamente, ao tema Informação e Conhecimento na era digital.

E há quem fale, ainda, em era da "Pós Informação", onde "o que tem é um público de uma única pessoa. É a caracterização, na opinião do referido autor, do ser digital, ou seja, uma unidade demográfica composta de uma só pessoa" (NEGROPONTE, 1995, p. 158), oferecendo ausência de simultaneidade na troca de informação.

O indivíduo, "imerso nesse espaço tridimensional" (CADOZ, 1997, p. 7), o cyber espaço, de alto nível de conectividade e informação, tem a sensação de que "acessar um computador do outro lado do mundo não é mais difícil do que acessar um computador na sala ao lado" (MONTES, Anais, 2001, p. 141).

Tamanha é a interação e abreviamento dos espaços e geografia, fazendo com que se tenha acesso ao mundo sem sair de casa e, no caso dos processos eletrônicos, acesso ao fórum, protocolo etc., sem sair do escritório.

Ocorre que em que pese os benefícios do avanço tecnológico, criando supercomputadores, redes mundiais e softwares de última geração, "surgiram problemas que variam desde a invasão de privacidade, falta de segurança dos dados até o desrespeito ao direito autoral" (ROCHA e CUSTÓDIO, Anais, 2001 , p. 17). Por isso, atento à proposta trazida pelo sistema computacional e Internet - da síntese essencial entre o signo e 0 ato, a representação e a ação (CADOZ 1997, p. 95) - convém redobrar o conhecimento e vigilância nessa virtualidade que se põe à frente.

No entanto, é preciso destacar a relação entre as ferramentas existentes hoje e a questão da novidade, de uma "suposta" nova realidade. Explica CADOZ (1997, p. 9) que:

O computador é apenas um meio de representação, o mais universal que o homem elaborou. $O$ que é novo é o grau de integralidade da representação que ele permite atingir e o uso que dele podemos fazer. O que não mudou é que só se trata de representação; as pinturas parietais do paleolítico superior eram também representações, elas utilizavam técnicas elaboradas para a época e tinham um papel preciso na vida e funcionamento das comunidades pré-históricas.

Por razão, seria intrigante questionar se essa realidade, essa sociedade em si seria mesmo nova, ou se apenas o meio de representação, com o auxílio tecnológico é que é verdadeiramente novo.

Nada obstante, sendo ou não apenas o meio de representação realmente novo, evidente é a sensação de novidade, seja com novas propostas 
de produtos cada vez mais elevados a nível digital, com repressão "forçada" dos analógicos, seja na seara biométrica ou, ainda, precisamente, no campo do Direito, elevando os processos materializados a processos digitalizados, virtuais. De fato, uma realidade presente.

\title{
3 TECNOLOGIA E JUDICIÁRIO
}

Não é de hoje que a celeuma da ineficiência do Poder Judiciário (e da justiça) assola os operadores e usuários do Direito. Já nos anos 60, com o Projeto Florença, CAPPELLETTI (1988, p. 36) liderou um movimento de estudo das causas da ineficiência do Poder Judiciário e, desde então, muitos autores se dedicaram a matéria, inclusive com ideais de gestão da justiça e novo gerenciamento dos procedimentos judiciais. Para ALMEIDA FILHO (2007, Prefácio):

\begin{abstract}
Embora o conhecimento de um problema seja o primeiro passo para a sua efetiva solução, em nosso país, o conhecimento da absoluta ineficiência do nosso sistema de prestação jurisdicional não tem gerado grandes resultados. Morosidade, dificuldade de acesso especialmente para os setores mais pobres da população, falta de transparência decisória em questões administrativas internas, existência de focos de corrupção de difícil eliminação, decisões contraditórias gerando um elevado grau de incerteza e insegurança jurídica, estrutura orgânica e atuação funcional marcadas pela ausência de racionalidade e modernidade, são realidades reconhecidas e admitidas, há muito tempo, como inerentes ao funcionamento da nossa máquina judiciária.
\end{abstract}

Analisando essa questão, ATAIDE JR. (Em artigo publicado no Jornal $O$ Estado do Paraná, em 15/08/2004):

Uma revolução operacional nos serviços judiciários foi iniciada com a introdução da máquina de escrever e da tipografia. O processo continuou escrito, mas agora mais ágil, posto que datilografado e com padrões impressos. Esses novos autos imperaram nos cartórios judiciais até o fim do século XX e, apesar de não totalmente extintos, já foram, na sua maioria, substituídos pelos autos confeccionados a partir de peças digitadas, ou seja, produzidas através de programas de computador. Uma nova realidade se descortinou com a utilização dos computadores nos trabalhos judiciários.

$[\ldots]$

Mas mesmo com as constantes inovações tecnológicas, não se venceu o paradigma dos autos escritos, de papel e plástico, entulhando prateleiras e escaninhos, obrigando seu transporte por meios dispendiosos, sem falar dos galpões e depósitos necessariamente alugados ou comprados pelos Tribunais para arquivar os autos findos.

$[\ldots]$

O século XXI parece reservar, no entanto, uma terceira revolução na prestação dos serviços judiciários: a eliminação do papel, o fim dos autos escritos. Mas como então documentar os atos processuais? Através dos autos virtuais. Petições, documentos, citações, 
despachos, sentenças e outros atos processuais realizados todos por computadores interligados em rede ou pela internet.

[...]

Tudo sem uma folha de papel, sem um pingo de tinta, sem demora, sem gastos desnecessários. Eficiência.

Essa é a idéia proposta com a implantação dos processos eletrônicos. Justamente pela idéia de adequação e re-conceituação do mundo em todas as suas esferas pelos avanços tecnológicos e científicos, o Direito e também o Poder Judiciário são chamados a integrar o rol dessas inovações, acolhendo os novos direitos que emergem das negociações eletrônicas, comprovação material por e-mail, dentre outros, acolhendo também dentro de sua própria estrutura - o Poder Judiciário - essas tecnologias que tanto auxiliam na diminuição do tempo e custos do processo, além da maior praticidade, agilidade e conforto que o mundo digital proporciona. Neste sentido BEHRENS (2005, p. 12):

\begin{abstract}
O Direito tem sido constantemente desafiado a acompanhar o envolvimento social com estas novas tecnologias. A ciência jurídica, está sendo provocada a criar normas, que não apenas devem repassar danos ou impedir comportamentos abusivos mas que evitem práticas que atentem contra os interesses individuais e coletivos, produzindo regras suficientemente flexíveis para que sejam capazes de acompanhar o desenvolvimento tecnológico.
\end{abstract}

Com esse intuito, o legislador pátrio desenvolveu, a partir de 1999, alguns indícios e primeiras premissas para o desenvolvimento e implantação dos processos eletrônicos como temos hoje.

Nada obstante é a Lei 11.419/2006 que estabelece, oficialmente ${ }^{11}$, o ingresso do Poder Judiciário na era digital, com a instituição efetiva de um processo eletrônico em âmbito nacional. Por meio desta Lei fica permitido o uso do meio eletrônico na tramitação de processos judiciais, comunicação de atos e transmissão de peças e documentos, na seara civil, penal e trabalhista, bem como nos juizados especiais - que já vinham atendendo a essa proposta - conforme as exigências legais referentes à comunicação eletrônica, ao processo eletrônico em si - onde o Judiciário deverá desenvolver sistemas de processamento de demandas judiciais, visando o acesso ininterrupto; a padronização e a agilidade na tramitação.

Assim, tamanha é a consciência de celeridade, inovação e adequação tecnológica trazidas com a Lei 11.419/2006, que os dados do Juizado Especial "Virtual" do Tribunal Regional Federal da 1 $1^{a}$ Região apontaram em 2007 um volume muito maior de processos virtuais julgados do que quando se implantou a proposta. No entanto, ainda que se tenha avanço tecnológico dentro do sistema judiciário, há muitas questões a serem problematizadas por intervenção da tecnologia.

Além das questões de acesso - tratadas oportunamente neste trabalho - a segurança também é assunto de extrema importância ao programar-se um sistema de alta tecnologia para uso e trabalho do Poder Judiciário. Conforme explica MONTES (Anais, 2001 p. 141): 


\begin{abstract}
A segurança de um sistema de informação e das redes que o compõem não pode ser "garantida" por um único mecanismo de defesa. Muitos acreditam que a utilização de um firewall é suficiente para proteger um site contra qualquer tipo de ameaças. Mas o nível de segurança de um site está relacionado a profundidade com que mecanismos de segurança são empregados.
\end{abstract}

Assim, se há necessidade de vários mecanismos de segurança para confiabilidade e integridade ${ }^{12}$ de um site, imagine-se em relação a um programa especializado, diretamente conectado com vários usuários e não imune às adulterações e fraudes de terceiros interessados ou não (intrusão ${ }^{13}$ ).

Dessa forma, ainda que sejam valiosas as disposições nas legislações atinentes ao avanço tecnológico do Poder Judiciário - amenizando o problema da ineficiência e acelerando a prestação jurisdicional -, há muito que se aprimorar na seara técnica de acesso, usuário, regulamentação e integridade documental.

Justamente por essa razão as legislações acima trabalham com matérias a serem regulamentadas por lei específica. E aqui, grande valor deve ser conferido a outras áreas do saber, principalmente a informática, ciência da computação, estatística, as quais poderão promover meios adequados de utilização do programa, aprimoramentos ao programa, sistemas de defesa etc.

\title{
4 SISTEMAS COMPUTACIONAIS PARA O JUDICIÁRIO
}

Sendo o Poder Judiciário um prestador de serviços, essa prestação deve ser a mais eficiente possível, evitando-se não só os problemas da morosidade da Justiça, mas incorporando avanços tecnológicos, hoje previstos na quase totalidade dos objetos, mercadorias e serviços oferecidos à sociedade.

Mas a questão da implantação da tecnologia nos procedimentos do Estado não é sentida apenas no Poder Judiciário. No Brasil, se consagrou a assertiva da ineficiência dos serviços médicos públicos por ausência de medicamentos e equipamentos avançados para cirurgias e demais procedimentos. Fazendo com que a população que possui melhores condições financeiras se valha de serviços médicos particulares com clínicas modernas, informatizadas, com aparelhos de sistemas digitais, equipes de pesquisa científica e tecnológica, implantando sistemas computacionais para um procedimento avançado de angioplastia, por exemplo.

Com relação ao Poder Judiciário, a escolha entre o serviço público e o privado não é possível (excetuados os casos de métodos extrajudiciais de resolução de conflitos). E dessa maneira, toda a população demandante e operadores do Direito se vêem impelidos a atuar num Judiciário moroso, ineficiente e retrógrado.

Esse é um grande desafio do Direito e do próprio Poder Judiciário. Assim, se o Direito hoje não pode fechar os olhos aos novos direitos, inclusive 
na seara tecnológica e informática, também não pode o Poder Judiciário ser avesso à informatização, modernização de seus equipamentos, formas de proceder, desapegando-se do paradigma documental rumo à digitalização, processos eletrônicos e maior uso e acesso à Internet nesse sentido, quando possível (possibilidade esta que também deve ser prestada pelo Estado).

Em artigo publicado no XXI Congresso da Sociedade Brasileira de Computação, os pesquisadores em Engenharia da Produção e Informática (TAIT e PACHECO, Anais, 2001b, p. 17) apresentaram um projeto de arquitetura de sistemas de informação (ASI) para o setor público, observando as especificidades desse setor em termos de estrutura, tecnologia da informação e usuários.

$\mathrm{Na}$ realidade, o setor público, embora tenha essa especificidade de ser público, comporta os mesmos requisitos técnicos para um sistema computacional de uma entidade particular, quais sejam: usuários, servidores, conexão, infra-estrutura compatível, manutenção do programa, atendimento para dúvidas etc.

Sendo assim, um sistema computacional que comporte a imensa gama de usuários do Poder Judiciário, o qual não se resume nas partes, estendendose aos advogados, peritos, juízes e demais serventuários da justiça, poderá funcionar desde que tenha um grande suporte de base, para manutenção dos aplicativos, recepção dos documentos anexados, bem como um corpo de pessoas capacitadas para verificação do programa e treinamento.

Exigindo-se, também, um bom investimento em maquinário avançado para que se possa obter um retorno satisfatório de quem utilizar o programa.

No Brasil, a implantação de sistemas computacionais para o Judiciário deu-se primariamente nos Juizados Especiais Federais, por intermédio da Lei 10.259/2001 que além de criar esses novos órgãos no âmbito da Justiça Federal, permitiu o serviço de intimação das partes e petições por meio eletrônico (art. $8^{\circ}, \S^{\circ}$ ), marcando substancialmente o ingresso dos processos virtuais no âmbito dos Juizados Federais que, devido ao seu progresso e facilidades, fomentaram propostas no mesmo sentido - desenvolvendo-se sistemas computacionais de gerenciamento de processos eletrônicos - em âmbito também estadual, tomando dimensão nacional agora pela Lei $11.419 / 2006$.

Nada obstante, entende-se, em absoluto, que o processo eletrônico não deve e, tampouco irá, substituir de imediato o processo judicial representado por meio de autos de papéis. Talvez a longo prazo isso seria possível, mas não simplesmente de per si, senão com uma mudança radical na sociedade brasileira, conferindo maior distribuição de renda e poderio não só econômico das camadas mais populares, mas, sobretudo acesso cultural e social, ou, ao menos acesso à informação a respeito da existência das coisas e de como e para que elas funcionam. 


\title{
5 INCLUSÃO OU EXCLUSÃO DIGITAL?
}

Corroborando o que já foi sumariamente explicitado nos itens anteriores, a universalização da Internet e procedimentos nela realizados constitui um grande avanço tecnológico, além de promover o acesso e a integração.

Ocorre que nada obstante à barreira enfrentada em relação a ausência de padronização dos sistemas computacionais judiciários, outros entraves como o alto custo da plataforma computacional (GUEDES NETO, Anais, 2001b, p. 12) aliado ao diminuto índice de informação da população, ao invés de proporcionar a inclusão digital pode vir a estabelecer uma verdadeira exclusão social - a infoexclusão.

Aclarando o sentido da expressão, NAZARENO, BOCCHIO, MENDES e PAZ FILHO (2007, p. 14):

\begin{abstract}
Embora na sua acepção original o termo "inclusão digital" tenha sido utilizado somente para distinguir situações de desigualdade no acesso à Internet (o "provimento assimétrico na sociedade de instrumentos de acesso a serviços na web"), recentemente a expressão vem sendo mais bem lapidada, tendo sua abrangência ampliada. Atualmente, ela é empregada para indicar "falhas no provimento pelos governos de acesso universal a serviços de informação e comunicação, indistintamente, a todos os cidadãos".
\end{abstract}

De fato, com o avanço da informática e tecnologia, bem como da relação destas com o meio em que vivemos, ímpeto natural do homem foi a atribuição de um status especial a esse sistemas digital. A esse respeito leciona BEHRENS (2005, p. 12):

A evolução tecnológica torna ainda mais evidente a diferença de acesso a recursos eletrônicos e informacionais, aumentando a distância entre as diferentes classes sociais, deixando transparecer os problemas econômicos e não apenas comerciais. A exclusão digital é uma realidade que precisa ser pelo Direito combatida, para que se possa manter o equilíbrio social e proporcionar a todos as mesmas oportunidades de acesso e desenvolvimento cultural.

Por isso diz-se que o desafio político global do mundo não está em superar a exclusão digital, mas expandir o acesso e o uso da tecnologia para a promoção da inclusão social (WARSCHAUER, 2006. p. 282). Isso porque, no Brasil e no mundo, a discrepância desse acesso e desenvolvimento cultural é flagrante. Na seara da tecnologia há autores que defendem até um "apartheid digital" entre as regiões geográficas brasileiras (NAZARENO, BOCCHIO, MENDES e PAZ FILHO, 2007, p. 33) e as demais regiões do globo terrestre países desenvolvidos e subdesenvolvidos ${ }^{14}$. E as razões para tal disparidade envolvem questões de economia, infra-estrutura, política, educação e cultura (WARSCHAUER, 2006, p. 80).

Atento a essa proposta de inclusão digital, o Governo Nacional intentou alguns projetos neste sentido. O Programa Nacional de Informática na Educação - Prolnfo, criado em 1997, objetivou a informatização das escolas de 
nível fundamental e médio. O Programa Sociedade da Informação - Socinfo, lançado em 1999, disseminava a adaptação da sociedade às novas tecnologias, bem como a implantação de projetos piloto nesse sentido. $O$ Computador Popular, iniciado em 2000 no DCC-UFMG, permitia o acesso à Internet a partir de linha discada ou rede local e a execução de aplicativo Linux neste caso. O Governo Eletrônico Serviço de Atendimento ao Cidadão Gesac, criado em 2002, promoveu a instalação de pontos de acesso público à Internet, gratuitamente, estabelecendo conexão com o Programa Casa Brasil, que visa não só a inclusão digital, mas, sobretudo, a social. Tem ainda os Telecentros, criados também nesta época; o Projeto Aliança para a sociedade da Informação - Alis; o Projeto Paraná-Digital; o Governo Eletrônico ou EGoverno e os Centros Vocacionais Tecnológicos implantados a partir de 2003, promovendo o ensino e a profissionalização no conhecimento científico e tecnológico.

E nesta mesma linha, a criação da Frente Parlamentar do Software Livre, com o intuito de modificar a cultura de uso de software no Brasil, conscientizando as pessoas das vantagens sociais e econômicas da disseminação do uso de sistemas livres no país.

Assim, o Governo brasileiro objetivou não só a inclusão digital e social, mas promoveu ainda outros projetos ${ }^{15}$ nesse sentido, utilizando-se de ferramentas tecnológicas acessíveis e orçamento compatível.

Ocorre que, em que pese a consciência e fomento da inclusão digital, a própria sociedade brasileira ainda é incipiente nos debates acerca da segurança, acesso e informatização ${ }^{16}$, por exemplo. Embora a sociedade tenha passado pelos estágios revolucionários da imprensa, energia elétrica e criação dos computadores, alguns conceitos básicos de informação e interpretação da informação dada ainda são muito complexos e de difícil assimilação para as camadas menos favorecidas. Algumas delas, tampouco entendem porque devem aderir ao programa governamental e aprender a utilizar a internet. Para essas pessoas o próprio computador é muito distante de sua realidade.

E ainda subsistem os problemas oriundos do custo da infoinclusão que, no Brasil estima-se uma média de US $\$ 6,00$ por habitante, adicionando-se outros custos a título de manutenção, capacitação e treinamento (NAZARENO, BOCCHIO, MENDES e PAZ FILHO, 2007, p. 105), o que indica a necessidade de investimentos em infra-estrutura, orçamento e políticas públicas para a inclusão de toda a parcela populacional infoexcluída.

De fato, a inclusão digital não se resume no binômio "equipamento conectividade", pois nem sempre o recurso físico (computador) e digital (internet) compreende os recursos humanos e sociais ${ }^{17}$. Até porque a questão do acesso à internet não diz respeito somente ao campo das oportunidades que poucos possuem, mas essencialmente "pela sua lógica comercial, por sua política de difusão e pelo próprio desenvolvimento tecnológico em si" (GUERREIRO, 2006, p. 151) que, fatalmente, acaba por excluir várias camadas sociais. Neste sentido BEHRENS (2005, p. 94-95): 
Portanto, frutos dessa nova realidade, nasceram os "excluídos digitais". Ou seja, enquanto indivíduos de classes sociais mais altas, passam seus dias interagindo, informando-se e criticando situações e conteúdos de sites, os indivíduos de classes mais pobres estão, muitas vezes, longe desta realidade informática e informacional.

Analisando-se as premissas da exclusão digital para a inclusão social, WARSCHAUER (2006, p. 31) aponta a nova economia da informação e a nova sociedade de rede, o papel decisivo da tecnologia em todos os aspectos dessa nova economia e sociedade, bem como o acesso a essa tecnologia que, "pode ajudar a determinar a diferença entre a marginalização e inclusão nessa nova era socioeconômica".

Em 2004, o Instituto Brasileiro de Direito Eletrônico, realizou o I Congresso de Direito Eletrônico, em Petrópolis-RJ, debatendo as diretrizes para uma política de inclusão digital e respeito aos Direitos Humanos. Na III edição do Congresso, a ser realizada em Maringá-PR, em outubro/2008, terá como enfoque o processo eletrônico e suas possibilidades de aperfeiçoamento; o comércio eletrônico; o software livre e a aplicação do Direito nas atuais formas de pensar na cybercultura, dentre outros temas. (http://www.ibde.org.br.). E há mais propostas futuras no sentido da inclusão digital como a disseminação do ONID (Observatório Nacional de Inclusão Digital), com informatização inclusive de escolas indígenas, a exemplo da parceria entre a Secretaria de Educação e o Governo do Maranhão; e o Projeto "Freqüência Digital" para controle de presença de alunos das escolas públicas brasileiras, bem como a proposta de um cadastro único da população brasileira para fins de localização e identificação de todo cidadão.

A par dessas perspectivas de inclusão digital-social, conclui GUERREIRO (2006, p. 203):

A inclusão digital é uma necessidade caracterizada pelo fato de a
maior parte da sociedade mundial não ter acesso aos benefícios
tecnológicos difundidos na sociedade mundial de informações. A
necessidade, por sua vez, é uma condição primordial no ser humano
- e, portanto, sempre existirá como estrutura que impulsiona a
sociedade para o futuro.

De forma a afirmar-se a inevitabilidade de uma mudança social que possa garantir uma adequação tecnológica sem esquecer da adequação social, com educação, acesso e informação. Isso, num primeiro momento pode parecer um tanto utópico, mas como já disse MORIN (In "Uma Mundialização Plural", MORAES, 2005, p. 366), "é possível manter a esperança na desesperança".

E é nessa desesperança atual de um avanço tecnológico cada vez maior e populações cada vez mais miseráveis, desculturalizadas e desinformadas que coloca-se a esperança de uma sociedade atual, desenvolvida econômica e tecnologicamente, mas garantindo a tão sonhada inclusão digital e, principalmente, social. 


\title{
CONCLUSÕES
}

A perspectiva de expansão da internet no mundo é imprevisível (GUERREIRO, 2006, p. 150). O padrão de mudança social normal, dependente de mecanismos nacionais e êxito na acumulação de capital, asseguram de certa forma as aspirações humanas por meio de paliativos concedidos pelo Estado de melhora do Judiciário, melhora da Educação, melhora do acesso, mas não rompem efetivamente com conceitos e estruturas sedimentadas pela modernidade, implementando o gerenciamento, a (re)organização e estruturação dos procedimentos judiciais para atingir efetivamente o acesso e a inclusão social.

E nesta seara da inovação, CADOZ (1997, p. 96) explica que:

Progressos tecnológicos ainda estão por vir. As décadas futuras mostrarão, é certo, transformações que hoje nem sequer podemos imaginar. Não devemos, contudo, vislumbrar um estágio definitivo ainda que longínquo, no qual teríamos, no que chamamos aqui a máquina, uma representação total do universo.

Assim, compreende-se salutar as inovações tecnológicas por que passa o Poder Judiciário, por meio da implantação de sistemas capazes de gerenciar dados e processos judiciais, trazendo agilidade, facilidade, menor tempo, menor custo e adequação tecnológica. No entanto, as modificações permanecerão existindo, tanto interiormente - com modernização dos equipamentos, procedimentos e do próprio sistema computacional - como exteriormente, com propostas de maior acesso da população, almejando uma efetiva inclusão digital e social.

\section{THE INTERNET AND SOCIAL INCLUSION: REFLECTIONS ON THE USE OF THE COMPUTING SYSTEMS JUDICIARY IN THE CONDUCT OF "INFOINCLUSION"}

\begin{abstract}
With technological changes, major impact on society, the Law and the Judiciary are challenged to adapt their procedures, redesign concepts and meet the multifarious demands that you are betting. In fact, if the social reality is no longer the same, and the advance of technology and information technology change substantially the most diverse branches of society, the judiciary and public service provider may not be averse to this issue, should also, in addition to enabling integration and use of computer systems in pursuit of speed, strength and lower cost procedure, worried about the issue of access of the
\end{abstract}


population not only to this new reality technology, but also access to information, knowledge, computerization and the very Justice. In crotch, much has yet to design and deploy to try to accommodate the entire population, making this digital inclusion becoming nothing more than an exclusion. Hence the need for ever more, modernize all spheres state, including adjusting the Judiciary is the fact that the digitalization and computerization of the systems used, but do not forget are the less advantaged sections.

Keywords: Computer systems. Digital inclusion. Judiciary. Social Inclusion. Technology.

\section{NOTAS}

* Mestranda do Programa de Pós-Graduação em Direito (PPGD) da PUCPR. E-mail: alexiabrotto@hotmail.com

* Doutora em Informática. Professora Titular da Pontifícia Universidade Católica do Paraná PUCPR para os cursos de Ciência da Computação, Engenharia da Computação e Direito. Professora dos Programas de Pós-Graduação em Direito e do Programa de PósGraduação em Informática Aplicada da mesma instituição. Pesquisadora CNPq - Nível II, cinthia.freitas@pucpr.br.

1 "As novas tecnologias mudam a trajetória dos acontecimentos sociais, alterando sensivelmente a cultura local e concorrendo com as tecnologias já existentes e com tudo o que se aprendeu antes. Toda inovação tecnológica surge a partir de conhecimentos já existentes, e estes são originários dos avanços da manufatura, que cedeu lugar à tecnofatura. Toda tecnologia é social por excelência. Começa com uma necessidade local e soluciona um obstáculo de desenvolvimento social universalizado, consistindo, dessa forma, não apenas em ferramentas e aplicativos, mas em processos e soluções a serem implementados." (GUERREIRO, 2006, p. 169-170).

2 Neste sentido: "Juntas, ciência e técnica não param de surpreender e revolucionar. Mas, esta ciência vencedora é simultaneamente hegemônica e precária. O capitalismo global apossou-se por completo dos destinos da tecnologia, libertando-a de amarras metafísicas e orientando-a única e exclusivamente para a criação de valor econômico. Transformados em fator fundamental na disputa dos mercados e na acumulação capitalista global, os vetores tecnológicos se autonomizaram definitivamente de considerações de natureza ética, social ou de políticas públicas" (DUPAS, Anais, 2001b, p. 4).

3 "A complexificação multidimensional que opera a emergência duma microestrutura nova [...] opera igualmente a emergência duma macroestrutura, que faz estoirar o quadro fechado da paleossociedade, alarga e enriquece a esfera demográfica da organização social." (MORIN, 1973, p. 157-158).

4 Ao analisar o fenômeno da mudança paradigmática da ciência e do direito, BEHRENS (2007, p. 113 e 115) entende que "o paradigma das complexidades vem alertar a comunidade em geral para a necessária inclusão social na busca de convivência pacífica da humanidade na comunidade mundial, especialmente, na tentativa da superação de conflitos entre os povos, de neutralização de processos de violência e de supressão das atitudes de agressão à natureza e aos seres vivos. [...] O paradigma da complexidade absorve características fortemente enfocadas na visão de totalidade, de interconexão, de inter-relacionamento, e, especialmente, na superação da visão fragmentada da sociedade".

5 "O que está hoje a morrer não é a noção de homem, mas sim a noção insular do homem, separado da natureza e da sua própria natureza (...). Dobram os sinos por uma teoria fechada, fragmentária e simplificante do homem, Começa a era da teoria aberta, multidimensional e complexa." (MORIN, 1973, p. 193).

"Sujeito concreto e cidadania não se assentam na razão de uma compreensão exclusivamente abstrata do sujeito: passa a ter sentido o plano do seu conteúdo, bem como suas projeções concretas. Com isso, é possível afirmar que, quando a Constituição Brasileira de 1988 tutela o direito a vida - e coloca em um primeiro grau o direito de 
personalidade -, situando em um primeiro patamar o sujeito, não está fazendo homenagem àquele sujeito abstrato do sistema clássico. Refere-se a um novo sujeito, alguém que tenha uma existência concreta, com certos direitos constitucionalmente garantidos: vida, patrimônio mínimo (que compreende a habitação) e sobrevivência." (FACHIN, 2003, p. 189).

7 "O Poder Judiciário, antes periférico na práxis republicana, tem assumido novos papéis e repensando as suas estratégias. Nas democracias consolidadas, ele não apenas terá que responder ao anseio dos que se encontram à margem da afluência material e comunicacional daquelas sociedades, mas, em o fazendo, contribuir para a regeneração dos institutos pelos quais a liberdade pôde ser vivida, até aqui, como grande promessa da modernidade. Nas democracias mais recentes, ainda em processo de consolidação, os desafios se multiplicam - são maiores os clamores por igualdade e, portanto, os virtuais percalços para a afirmação das instituições da liberdade." (VIANNA, 1999, contracapa).

8 "A maior parte dos movimentos sociais e políticos do mundo, de todas as tendências, usa a Internet como forma privilegiada de ação e organização. (...). A Internet é a estrutura organizativa e o instrumento de comunicação que permite a flexibilidade e a temporalidade da mobilização, mantendo, porém, ao mesmo tempo, um caráter de coordenação e uma capacidade de enfoque dessa mobilização." (MORAES, 2005, p. 277).

9 Segundo Castells (In MORAES, 2005, p. 256), "a primeira pesquisa séria sobre usuários da Internet, de fins de 1995, assinalava que havia cerca de 350 milhões de usuários em todo o mundo. As previsões conservadoras dão conta de em 2005-2007 chegaremos a 2 bilhões, no mínimo. É bem verdade que isso constitui apenas uma terça parte da população do planeta, mas isso quer dizer, ponderando em termos das sociedades mais desenvolvidas, que nas sociedades de nosso contexto as taxas de penetração estarão entre 75 e $80 \% "$.

10 "A grande expansão econômica internacional da segunda metade do século XIX está associada ao extraordinário desenvolvimento da tecnologia dos transportes: o motor a vapor, a ferrovia, os navios de casco de ferro, bem como aos avanços. nas comunicações e ao desenvolvimento da eletricidade. De modo análogo, o atual fenômeno da globalização está profundamente. vinculado ao desenvolvimento do transporte aéreo e das empresas transnacionais, à revolução nas comunicações e na tecnologia de computação, e às sinergias entre esses elementos-chave do processo." (PERIN JR, 2003, p. 47).

11 Neste sentido WAMBIER (2007, p. 294): "Diz-se oficialmente porque alguns atos processuais já vinham sendo realizados por meios eletrônicos, em virtude da iniciativa de poucos tribunais ainda que, às vezes, apenas para permitir a prática de atos pelas partes por meio de e-mail nos termos da Lei 9.800/1999. Os atos realizados nos termos desta lei, no entanto, dependem de confirmação, com a entrega de petição original no prazo legal. Não é possível afirmar, neste caso, que se está diante de um 'processo eletrônico', no sentido ora empregado pela Lei 11.419/2006".

12 "A integridade dos arquivos de um sistema operacional é um fator crítico para a segurança do mesmo, pois, uma vez que ela não possa ser garantida, não há certeza da validade dos dados nele contidos e, por conseqüência, nem do seu comportamento. Por exemplo: uma vez que um agente malicioso obtenha algum tipo de acesso a um sistema, dependendo dos privilégios de acesso, ele poderá alterar, substituir ou mesmo incluir novos arquivos com o intuito de esconder os traços da invasão, garantir futuros acessos ou ainda alterar configurações de diferentes serviços a fim de obter um maior nível de acesso. Sem a garantia da integridade dos arquivos, essas ações maliciosas dificilmente serão notadas e o agente malicioso obterá sucesso em sua investida." (SERAFIM e WEBER, Anais, 2001, p. 169).

13 "Detecção de intrusão é o processo de identificar e responder a atividades mal intencionadas, direcionadas para recursos computacionais e de rede." (AMOROSO, 1999, p. 218).

14 Conforme dados do Comitê Gestor da Internet no Brasil. "A diferença numérica de acesso, uso e produção de conteúdos entre os países ricos e países pobres é assustadora. Atualmente $10 \%$ da população mundial possui acesso à web. Desse percentual, a maior parte está localizada nos Estados Unidos e Canadá, que concentram mais da metade dos usuários, ou seja, $68 \%$ e $64 \%$ da sua população, respectivamente. No lado inverso desses números estão países do continente africano e o Brasil. No começo do século XXI, na África o número de internautas não chegava a $0,01 \%$ da população. No Brasil do ano 2000 , segundo dados do Livro Verde Brasil, de Tadao Takahashi (2000), 10\% da população 
possuía computadores e apenas cerca de 2,5\% tinha acesso à internet, sendo que, desse percentual, apenas $16 \%$ pertencia à classe $C$ e $4 \%$, à classe $D$.

Um ano depois, dados da Pesquisa Nacional por Amostra de Domicílio (PNAD) de 2001 mostravam que $12,46 \%$ da população brasileira possuía acesso ao computador e, desse percentual, 8,31\% tinha acesso à internet, mas cerca de 97\% dos incluídos digitais vivem em centros urbanos. Uma outra informação importante dizia respeito às etnias: os amarelos (descendentes de orientais) são o grupo de maior acesso proporcional $-41,66 \%$, seguidos pelos brancos $-15,14 \%$ e pardos $-4,06 \%$. Esses dados, entre outros, deram origem ao Mapa da Exclusão Digital, publicado em 2003, o primeiro estudo nos diversos segmentos da sociedade relacionados às tecnologias de informação e comunicação (TICs), que levam em consideração o capital físico (máquinas e softwares) e o capital humano, através da capacitação e da educação para o desenvolvimento social. Números mais recentes (2004) revelam que o Brasil está na oitava posição entre os países com maior número de hospedagens na internet e é o décimo país com maior número de internautas, mas ainda assim esse número representa apenas $0,8 \%$ da população." (BARBOSA FILHO, CASTRO e TOMÉ, 2005, p. 274-275).

15 Exemplos de Projetos de Lei em tramitação do Parlamento brasileiro que versam sobre tecnologia e acesso à população. PL $n^{\circ}$. 4.275/2001; 1.739/2003; 2.066/2003; 2.417/2003; 2.427/2003; 2.521/2003; 3.280/2004; 3.684/2004; 3.785/004.

16 "É nessa perspectiva que se exerce a pressão para que se aba um debate público sério sobre o papel da comunicação e da mídia em nossas sociedades. E paradoxal que, enquanto o discurso oficial não pára de repetir que as NTIC transformaram profundamente as nossas vidas, não tenham se estabelecido, ao mesmo tempo e conseqüentemente, mecanismos e espaços para que a sociedade se pronuncie a respeito." (MORAES, 2005, p. 414).

17 Para WARSCHAUER: "O letramento e a educação afetam o acesso on-line tanto nos níveis macro como nos micro. No macronível, o letramento e a educação em massa servem para acelerar a força motora do desenvolvimento econômico, e, assim, criar condições para uma tecnologização maior da sociedade [...]. A educação e o letramento também são importantes no micronível individual, já que as habilidades de leitura, escrita e pensamento continuam sendo decisivas para a capacidade de utilização da internet. A educação também ajuda a determinar como as pessoas usam a internet e os benefícios que elas obtêm disso". Além disso, "para as pessoas cuja rede social não inclui usuários de computador, os desafios de comprar, configurar e aprender a utilizar um computador podem ser opressivos". (WARSCHAUER, 2006, p. 151-152 e 212).

\section{REFERÊNCIAS}

ALMEIDA FILHO, José Carlos de Araújo. Teoria Geral do Processo Eletrônico. Rio de Janeiro: Forense, 2007.

AMOROSO, E. G. Intrusion Detection: Na Introduction to InternetSurveillance, Correlation, Traps, Trace-Back, and Response. New Jersey: Intrusion. Net Books, 1999.

ANAIS DO $3^{\circ}$ SIMPÓSIO SOBRE SEGURANÇA EM INFORMÁTICA - SS1. 2001. São José dos Campos -SP: Clovis Torres Fernandes Editor, 24 a 26 de outubro de 2001.

ANAIS DO XXI CONGRESSO DA SOCIEDADE BRASILEIRA DE COMPUTAÇÃO - SBC 2001. Fortaleza: Editado por Ana Teresa Martins, 30 de julho a 03 de agosto de 2001. (b) 
BARBOSA, Cláudia Maria. Poder Judiciário: reforma para quê. Âmbito Jurídico, v. 46, p. 2339, 2007. Disponível em: http://www.ambitojuridico.com.br. Acesso em: 28/05/2008.

BARBOSA FILHO, André; CASTRO, Cosette; TOMÉ, Takashi. Mídias Digitais: Convergência Tecnológica e Inclusão Social. São Paulo: Editora Paulinas, 2005.

BARRETO, Ângela Maria. Informação e conhecimento na era digital. Transinformação, Campinas, v.17, n.2, p. 111-122, maio/ago 2005.

BEHRENS, Fabiele. A Assinatura Eletrônica como Requisito de Validade dos Negócios Jurídicos e a Inclusão Digital na Sociedade Brasileira. Curitiba: Dissertação de Mestrado PUC/PR, 2005.

Assinatura eletrônica e Negócios Jurídicos. Curitiba: Juruá, 2007.

CADOZ, Claude. Realidade Virtual. São Paulo: Editora Ática, 1997.

CAPPELLETTI, Mauro. Proceso, Ideologias, Sociedad. Tradicción de Santiago Sentis Melendo y Tomás A. Banzhaf. Buenos Aires: Ediciones Juridicas Europa-America, 1974.

CAPRA, Fritjof. A Teia da Vida: uma nova compreensão científica dos sistemas vivos. São Paulo: Cultrix, 1996.

CINTRA, Antônio Carlos de Araújo; GRINOVER, Ada Pellegrini; DINAMARCO, Cândido Rangel. Teoria Geral do Processo. 22. ed. revisada e atualizada. São Paulo: Malheiros, 2006.

DINAMARCO, Cândido Rangel. A Instrumentalidade do Processo. 11. ed. revisada e atualizada. São Paulo: Malheiros Editores, 2003.

. Instituições de Processo Civil. Vol I. 5. ed. revisada e atualizada. São Paulo: Malheiros Editores, 2005.

. Instituições de Processo Civil. Vol II. 5. ed. revisada e atualizada. São Paulo: Malheiros Editores, 2005. (b)

FACHIN, Luiz Edson. Limites e Possibilidades da nova Teoria Geral do Direito Civil. Revista da Faculdade de Direito, Curitiba, ano 27, n 27, 1992/1993.

GUERREIRO, Evandro Prestes. Cidade Digital: Infoinclusão social e Tecnologia em rede. São Paulo: Editora Senac, 2006.

IANNI, Octávio. Globalização: Novo Paradigma das Ciências Sociais. São Paulo: Estudos Avançados, 1994.

JAQUES, Paulino. Curso de Direito Constitucional. Rio de Janeiro: Editora Forense, 1958.

LEAL, Sheila do Rocio Cercal Santos. Validade jurídica dos contratos eletrônicos via internet. Curitiba: Dissertação Mestrado PUC/PR, 2003.

MARINONI, Luiz Guilherme; ARENHART, Sérgio Cruz. Curso de Processo Civil. Vol 2 - Processo de Conhecimento. 6. ed. São Paulo: Editora Revista dos Tribunais, 2006.

MORAES, Dênis de. Por uma outra Comunicação: Mídia, Mundialização Cultural e Poder. Rio de Janeiro: Editora Record, 2005. 
MORIN, Edgar. O Paradigma Perdido: a natureza humana. Portugal: Publicações Europa - América, 1973.

MOURA, Alexandrina Sobreira de. (Organizadora). O Estado e as Políticas Públicas na Transição Democrática. São Paulo: Editora Revista dos Tribunais/Vértice, 1989.

NAZARENO, Cláudio; BOCCHIO, Elizabeth Veloso; MENDES, Fábio Luis; PAZ FILHO, José de Souza. Tecnologias da Informação e Sociedade: O Panorama Brasileiro. Brasília: Editora Plenarium, 2007.

NEGROPONTE, Nicholas. A vida digital. 2. ed. São Paulo: Companhia das Letras, 1995.

NERY JR. Nelson. Princípios do Processo Civil na Constituição Federal. 3. ed. revisada, ampliada e atualizada. São Paulo: Editora Revista dos Tribunais, 1996.

PERIN JR, Ecio. A Globalização e o Direito do Consumidor: harmonização legislativa dentro dos mercados regionais. Barueri, SP: Manole, 2003.

PORTANOVA, Rui. Princípios do Processo Civil. 3. ed. Porto Alegre: Editora Livraria do Advogado, 1999.

SOUSA SANTOS, Boaventura de. A Crítica da Razão Indolente: Contra o desperdício da Experiência. São Paulo: Cortez, 2000.

TECGLEN, Eduardo Haro. A sociedade de consumo. Rio de Janeiro, Salvat Editora do Brasil, 1980.

TEIXEIRA, Sálvio de Figueiredo (Coordenador). As Garantias do Cidadão na Justiça. São Paulo: Saraiva, 1993.

WARSCHAUER, Mark. Tecnologia e Inclusão Social: A Exclusão Digital em Debate. São Paulo: Editora Senac 2006.

Recebido para publicação 24/10/2008

Aceito para publicação 15/01/2009 